\title{
Template-Assisted Ligand Encapsulation; the Impact of an Unusual Coordination Geometry on a Supramolecular Pyridylphosphine-Zn(II)porphyrin Assembly
}

\author{
Arjan W. Kleij, ${ }^{\S}$ Mark Kuil, ${ }^{\S}$ Duncan M. Tooke, ${ }^{\dagger}$ Anthony L. Spek, ${ }^{\dagger}$ and Joost N. H. Reek ${ }^{*, \S}$ \\ Van't Hoff Institute for Molecular Sciences, University of Amsterdam, Nieuwe Achtergracht 166, \\ 1018 WV, Amsterdam, The Netherlands and Department of Crystal and Structural Chemistry, \\ Bijvoet Center for Biomolecular Research, Utrecht University, Padualaan 8, 3584 CH, Utrecht, \\ The Netherlands
}

Received May 27, 2005

The tris(para-pyridyl)phosphine template (1) has been used in conjunction with a series of meso-substituted $\mathrm{Zn}$ (II)-tetraphenylporphyrins complexes $(2-10)$ to create supramolecular encapsulated ligand assemblies via $\mathrm{Zn}-\mathrm{N}_{\text {pyr }}$ interactions. The structural features of supramolecular ligand $1 \cdot[2]_{3}$ have been investigated in detail using X-ray crystallography, NMR specroscopy, and UVvis spectroscopy. The pyridylphosphine-porphyrin stoichiometry determined in solution (1:3) differs markedly with that observed in the solid state $\left(2: 5\right.$, for assembly $\left.[1]_{2} \cdot[2]_{5}\right)$. The difference originates from an unusual coordination behavior of one of the $\mathrm{Zn}$ centers, which is octahedrally surrounded through double axial coordination by the pyridyl groups of the two different molecules of 1 .

Porhyrins are widely used and highly versatile building blocks in (supramolecular) chemistry. ${ }^{1}$ In particular, the photophysical and catalytic properties of metalloporphyrin systems have been the subject of numerous investigations. ${ }^{2}$ One interesting application of metalloporphyrins can be found in catalysis, in which case the metal center is used as an active site. On the other hand, metalloporphyrins have been used to construct various supramolecular assemblies via coordinative patterns. Generally, axial coordination of $\mathrm{N}$-donor ligands to the metal center represents the supramolecular binding motif. This self-assembly strategy has been

* To whom correspondence should be addressed. E-mail: reek@ science.uva.nl

$\S$ University of Amsterdam.

$\dagger$ Utrecht University.

(1) (a) Imamura, T.; Fukushima, K. Coord. Chem. Rev. 2000, 198, 133. (b) Bélanger, S.; Keefe, M. H.; Welch, J. L.; Hupp, J. T. Coord. Chem. Rev. 1999, 190-192, 29. (c) Toma, H. E.; Araki, K. Coord. Chem. Rev. 2000, 196, 307. (d) Wojaczyñski, J.; Latos-Grazynski, L. Coord. Chem. Rev., 2000, 204, 113. (e) Suslick, K. S.; Rakow, N. A.; Kosal, M. E.; Chou, J.-H. J. Porphyrins Phthalocyanines 2000, 4, 407.

(2) (a) Mackay, L. G.; Wylie, R. S.; Sanders, J. K. M. J. Am. Chem. Soc. 1994, 116, 3141. (b) Anderson, H. L.; Bashall, A.; Henrick, K.; McPartlin, M.; Sanders, J. K. M. Angew. Chem., Int. Ed. Engl. 1994, 33, 429. (c) Wsielewski, M. R. Chem. Rev. 1992, 92, 435. (d) Balch, A. L.; Mazzanti, M.; Olmstead, M. M. Inorg. Chem. 1993, 32, 4737.

7696 Inorganic Chemistry, Vol. 44, №. 22, 2005 successfully applied for the construction of molecular squares, coordination polymers, and other types of structures. ${ }^{3}$ Porphyrins have also been used for supramolecular catalysis in which the metal centers in porphyrin building blocks are utilized as catalytic centers, as well as binding motifs. For instance, a Mn(III)porphyrin unit has been incorporated into a self-assembled superstructure and applied as a catalyst for the epoxidation of conjugated olefins, thereby giving rise to an increased catalyst performance. ${ }^{4}$ We reported a templated approach for the encapsulation of transition metal catalysts. Various $\mathrm{Zn}(\mathrm{II})$ - and $\mathrm{Ru}(\mathrm{II})-$ porphyrin complexes were used as supramolecular building blocks that selectively associate with the nitrogen donor atoms of a tris(meta-pyridyl)phosphine template, resulting in encapsulated phosphine ligands and their respective metal complexes. ${ }^{5}$ These sterically demanding phosphine ligands gave rise to selective mono-coordination in various transition metal complexes and consequently to enhanced reactivity and unexpected selectivities of the catalysts formed, particularly in the hydroformylation reaction. We recently showed that this concept can be extended to zinc(II)salphen building blocks and that the pyridylphosphine template structure (cf. 1, Scheme 1) controls the coordination geometry around the transition metal and thus the performance in

(3) (a) Stang, P. J.; Fan, J.; Olenyuk, B. Chem. Commun. 1997, 1453. (b) Drain, C. M.; Lehn, J.-M.; J. Chem. Soc., Chem. Commun. 1994, 2313. (c) Chichak, K.; Branda, N. R. Chem. Commun. 1999, 523. (d) Anderson, H. L.; Hunter, C. A. Sanders, J. K. M. J. Chem. Soc., Chem. Commun. 1989, 226. (e) Hunter, C. A.; Sarson, L. D. Angew. Chem., Int. Ed. 1994, 33, 2313. (f) Crossley, M. J.; Burn, P. L.; Langford, S. J.; Prashar, J. K. J. Chem. Soc., Chem. Commun. 1995, 1921. (g) Slagt, V. F.; Roeder, M.; Kamer, P. J. C.; van Leeuwen, P. W. N. M.; Reek, J. N. H. J. Am. Chem. Soc. 2004, 126, 4056. (h) Slagt, V. F.; van Leeuwen, P. W. N. M.; Reek, J. N. H. Chem. Commun. 2003, 2474.

(4) Merlau, M. L.; del Pilar, Mejia, M.; Nguyen, S. T.; Hupp, J. T. Angew. Chem., Int. Ed. 2001, 40, 4239.

(5) (a) Slagt, V. F.; Reek, J. N. H.; Kamer, P. J. C.; van Leeuwen, P. W. N. M. Angew. Chem., Int. Ed. 2001, 40, 4271. (b) Slagt, V. F.; Kamer, P. J. C.; van Leeuwen, P. W. M. N.; Reek, J. N. H. J. Am. Chem. Soc. 2004, 126, 1526.

10.1021/ic050858v CCC: $\$ 30.25$

(C) 2005 American Chemical Society Published on Web 10/04/2005 


\section{COMMUNICATION}

Scheme 1. Formation of Supramolecular Phosphine Ligands via $\mathrm{Zn}(\mathrm{II})-\mathrm{N}_{\mathrm{Pyr}}$ Interactions Using Various Zn(II)porphyrin Building Blocks

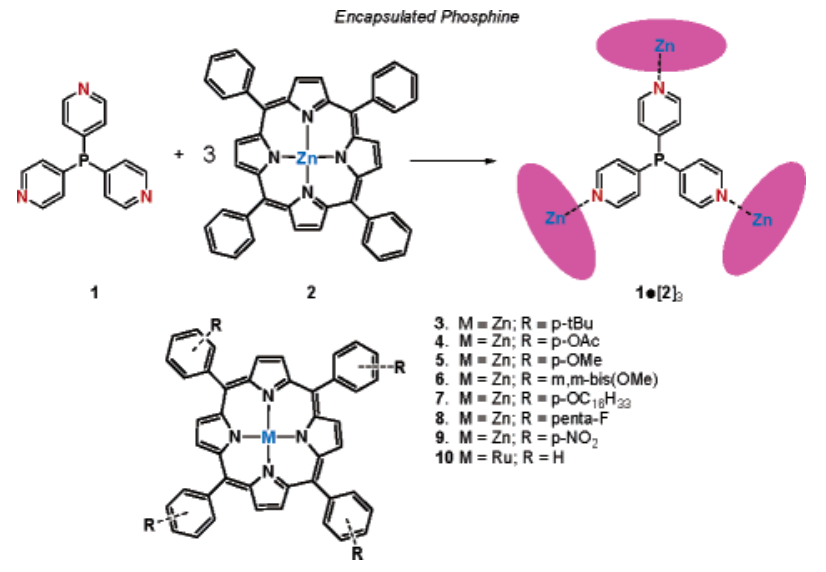

homogeneous catalysis. ${ }^{6}$ In this communication, we present an unusual solid-state structure of a tris(para-pyridyl)phosphine-porphyrin assembly and its relation to the solution-phase structure, as well as preliminary results of the application of these assemblies in the rhodium catalyzed hydroformylation of 1-octene.

Crystals were grown from $\mathrm{CH}_{2} \mathrm{Cl}_{2}$ /heptane by slow evaporation of a mixture of $\mathbf{1}$ and $\mathbf{2}$, present in a 1:3 ratio. Although the template-encapsulated structure was evidently formed, as is clear from the structure of the assembly presented in Figure 1, it did not have the expected 1:3 ratio of building blocks, but instead a 2:5 stoichiometry was observed. One of the $\mathrm{Zn}$ (II)porphyrin units is part of two adjacent capsule assemblies as a result of a rather unusual hexacoordinated zinc metal, leading to assembly $[\mathbf{1}]_{2} \cdot[\mathbf{2}]_{5}$. The structure can therefore be described as a fusion of two ' $1: 3$ ' assemblies through the central $\mathrm{Zn}$ (II)porphyrin unit. The unique hexacoordinated $\mathrm{Zn}$ center bridges the two parts of the 2:5 assembly via a double axial ligation of two pyridyl donors $\left(\mathrm{Zn}-\mathrm{N}_{\mathrm{pyr}}=2.4736\right.$ vs $\sim 2.20 \AA$ for the fivecoordinate $\mathrm{Zn}$ centers) of different molecules of $\mathbf{1}$. As a result of inversion symmetry, the $\mathrm{Zn}$ center is perfectly planar with the porphyrin $\mathrm{N}$ atoms of this unit, whereas in the other four $\mathrm{Zn}(\mathrm{II})$ porhyrins, the $\mathrm{Zn}$ centers reside, as usual, slightly out of the porphyrin plane $\left(\mathrm{N}_{\text {porph }}-\mathrm{Zn}\right.$ angles between $94^{\circ}$ and $101^{\circ}$ for $\mathrm{Zn}(2)$ and $94-103^{\circ}$ for $\left.\mathrm{Zn}(3)\right)$. The presence of both hexa- and pentacoordinate $\mathrm{Zn}$ (II)porphyrins within one supramolecular structure is very rare. ${ }^{7}$ The unusual structure is surprising because the association of a second pyridine ligand to $\mathrm{Zn}$ (II)porphyrins is known to be weak. ${ }^{8}$ Fajer et al. recently described two-dimensional supramolecular Zn(II)porphyrin assemblies with all-six-coordinated zinc centers linked through substituents with an axial $\mathrm{Zn}-\mathrm{N}$ distance of $2.473(5) \AA .{ }^{9}$ It is interesting to note that the current structure

(6) Kleij, A. W.; Lutz, M.; Spek, A. L.; van Leeuwen, P. W. N. M.; Reek, J. N. H. Chem. Commun. 2005, 3661.

(7) (a) Shukla, A. D.; Dave, P. C.; Suresh, E.; Das, A.; Dastidar, P. J. Chem. Soc., Dalton Trans. 2000, 4459. (b) Diskin-Posner, Y.; Kumar Patra, G.; Goldberg, I. J. Chem. Soc., Dalton Trans. 2001, 2775.

(8) PM3 calculations (Titan 1.05) on the bispyridyl zinc(II)porphyrin complex and its monopyridyl analogue indicate a difference of 14 $\mathrm{kcal} / \mathrm{mol}$ in favor of the latter species.

(9) Barkigia, K. M.; Battioni, P.; Riou, V.; Mansuy, D.; Fajer, J. Chem. Commun. 2002, 956.

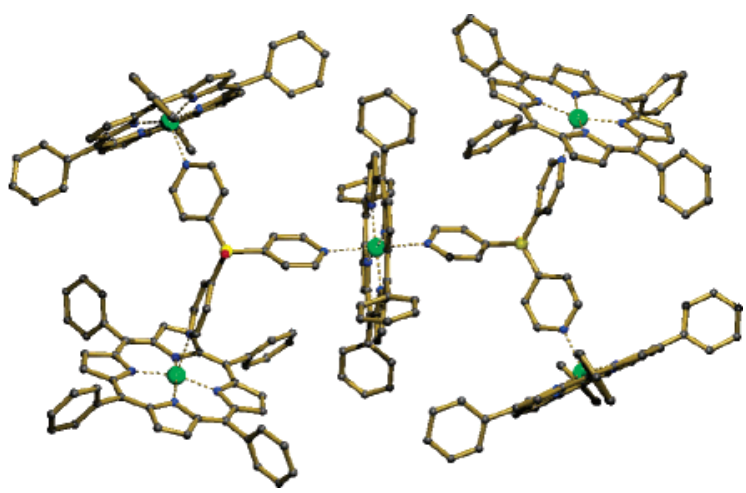

Figure 1. Plot of the molecular structure of $[\mathbf{1}]_{2} \cdot[2]_{5}$ in the crystal. Hydrogen atoms, co-crystallized solvent molecules, and numbering scheme have been omitted for clarity. Color scheme: green $=\mathrm{Zn}$, yellow $=\mathrm{P}$, blue $=\mathrm{N}$, gray $=\mathrm{C}$, red $=\mathrm{O}$. Selected bond distances $(\AA) /$ angles $(\mathrm{deg})$, esd's in parentheses: $\mathrm{Zn}(1)-\mathrm{N}(1)=2.4736, \mathrm{Zn}(2)-\mathrm{N}(2)=2.2056, \mathrm{Zn}$ $(3)-\mathrm{N}(3)=2.1931, \mathrm{~N}(1)-\mathrm{Zn}(1)-\mathrm{N}(5)=89.44, \mathrm{~N}(1)-\mathrm{Zn}(1)-\mathrm{N}(4)=$ 87.27, $\mathrm{N}(2)-\mathrm{Zn}(2)-\mathrm{N}(6)=98.83, \mathrm{~N}(2)-\mathrm{Zn}(2)-\mathrm{N}(7)=96.94, \mathrm{~N}(2)-\mathrm{Zn}-$ $(2)-\mathrm{N}(8)=94.83, \mathrm{~N}(2)-\mathrm{Zn}(2)-\mathrm{N}(9)=100.58, \mathrm{~N}(3)-\mathrm{Zn}(3)-\mathrm{N}(10)=$ $102.53, \mathrm{~N}(3)-\mathrm{Zn}(3)-\mathrm{N}(11)=103.16, \mathrm{~N}(3)-\mathrm{Zn}(3)-\mathrm{N}(12)=94.36, \mathrm{~N}(3)-$ $\mathrm{Zn}(3)-\mathrm{N}(13)=95.23$

is stabilized by four $\pi-\pi$ interactions between aryl rings of the central porphyrin ring and those of adjacent units.

The potential 3-fold rotational symmetry around the $\mathrm{P}(1)-$ $\mathrm{O}(1)$ bond is broken by the peripheral porphyrin systems at both sides of the molecule which are not superimposable. The phosphine atoms in the assembly were partially oxidized during the crystallization process, an observation that was quantified by ${ }^{31} \mathrm{P}\left\{{ }^{1} \mathrm{H}\right\}$ NMR spectroscopy ( 50\%).

The coordination behavior of pyridylphosphine $\mathbf{1}$ with meso-substituted $\mathrm{Zn}(\mathrm{II})$ tetraphenylporphyrin $\mathbf{2}$ in solution was further investigated using NMR and UV spectroscopy. NMR analysis of a 1:3 ratio of $\mathbf{1}$ and $\mathrm{Zn}$ (II)porphyrin $\mathbf{2}$ in $\mathrm{CD}_{2} \mathrm{Cl}_{2}$ indicated that the expected formation of multicomponent assembly $\mathbf{1} \cdot[2]_{3}$ had formed through $\mathrm{Zn}-\mathrm{N}_{\text {pyr }}$ interactions. Upon complexation of the pyridyl groups to the metalloporphyrin, a diagnostic upfield shift is observed for the protons $\mathbf{H}_{\mathbf{1}}$ and $\mathbf{H}_{\mathbf{2}}$ of the pyridyl unit $\left(\Delta \delta^{\mathbf{H 1}}=6.08 \mathrm{ppm}\right.$, $\left.\Delta \delta^{\mathbf{H} \mathbf{2}}=2.80 \mathrm{ppm}\right)$, caused by the shielding effect of the porphyrin. ${ }^{2,5}$ Only a marginal shift of the phosphorus resonance $\left(\delta=-9.41 \mathrm{ppm}, \Delta \delta=0.39 \mathrm{ppm}, \mathrm{CD}_{2} \mathrm{Cl}_{2}\right.$ ) was observed compared to $\mathbf{1}$, which confirms the selective axial binding of the pyridyl groups to the $\mathrm{Zn}$ (II) centers in solution. The ${ }^{1} \mathrm{H}$ NMR characteristics of crystalline $[\mathbf{1}]_{2} \cdot[2]_{5}$, after dissolving in $\mathrm{CD}_{2} \mathrm{Cl}_{2}$, also showed large upfield shifts for both protons (Figure 2). Signal integration confirmed the observed solid-state ratio $(2: 5)$ for $\mathbf{1}$ and 2 . The ${ }^{31} \mathrm{P}\left\{{ }^{1} \mathrm{H}\right\}$ NMR spectrum recorded for the crystalline material, dissolved in $\mathrm{CD}_{2} \mathrm{Cl}_{2}$, revealed the presence of nearly equimolar amounts (by signal integration) of the assembled phosphine and its oxidized parent compound and accordingly pairs of signals were observed for $\mathbf{H}_{1}$ and $\mathbf{H}_{2}$ in the ${ }^{1} \mathrm{H} \mathrm{NMR}$ spectrum (Figure 2)..$^{10}$

(10) From separate NMR experiments, we know that the change in chemical shifts for the pyridyl signals for $\mathbf{1} \cdot[\mathbf{2}]_{3}$ (compared to $\mathbf{1}$ ) is virtually identical for the oxidized form and that the difference in appearance under these conditions (shortage in porphyrin) is caused by the difference in affinity for the zinc(II)porphyrin. In this mixture, more of the $\mathbf{1} \cdot[2]_{3}$ complex is formed compared to its oxidized analogue. 


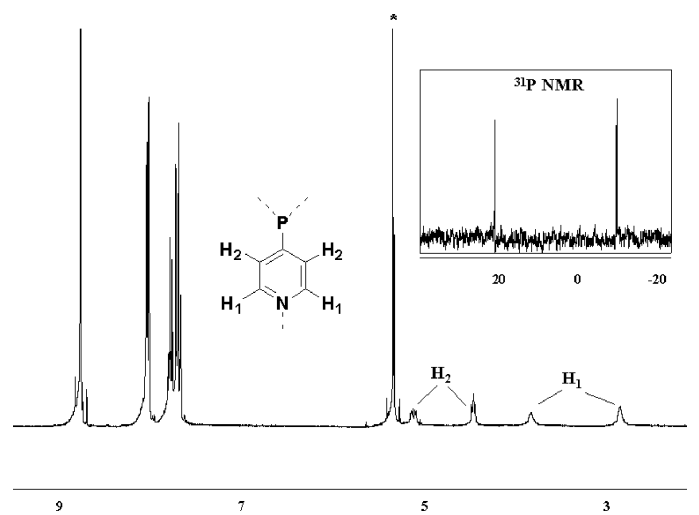

Figure 2. Selected region of the ${ }^{1} \mathrm{H}$ NMR spectrum recorded for the isolated and dissolved crystalline material $[\mathbf{1}]_{2} \cdot[2]_{5}$. The asterisk denotes the solvent residual peak. The inset shows the ${ }^{31} \mathrm{P}\left\{{ }^{1} \mathrm{H}\right\}$ resonances.

The solution-phase structure was further investigated by performing $\mathrm{UV}-$ vis titrations of $\mathbf{2}$ with $\mathbf{1}$ in toluene. As expected, these titration experiments showed that the $\mathbf{2}$-to-1 stoichiometry in solution is $3: 1$, which contrasts with the solid-state structure obtained (Figure 1). The titration curve was fitted against a 3:1 model to give the association constants of the first $\left(K_{1}=2.1 \pm 0.2 \times 10^{3} \mathrm{M}^{-1}\right)$, second $\left(K_{2}=2.3 \pm 0.2 \times 10^{3} \mathrm{M}^{-1}\right)$, and third binding $\left(K_{3}=1.9 \pm\right.$ $0.2 \times 10^{3} \mathrm{M}^{-1}$ ) of 2 to the tris-pyridylphosphine $\mathbf{1}$. The similarity of the $K_{\text {ass }}$ values indicates that in this assembly there exists no observable degree of cooperativity unlike we have previously observed for the assembly with tris(metapyridyl)phosphine as template. ${ }^{5}$

We have prepared a series of phosphine assemblies based on $\mathbf{1}$ and $\mathrm{Zn}$ (II)porphyrin building blocks $\mathbf{2 - 1 0}$, and these assemblies were applied as ligands for the rhodium-catalyzed hydroformylation of 1-octene (Table 1). It is clear that the activity and selectivity for the linear aldehyde product obtained using these $\mathrm{Rh}(\mathrm{I})$ catalysts derived from the phosphine assemblies (entries 2-10) resembles the parent phosphine 1 (entry 1). This implies that the assemblies based on tris(para-pyridyl)phosphine show typical behavior of bisphosphine-ligated $\mathrm{Rh}(\mathrm{I})$ complexes in hydroformylation. Furthermore, it appears that the activity of the supramolecular porphyrin-based catalysts can be regulated by the mesophenyl substituents.

Strong electron-donating ether-type substituents (entries 5-7) give rise to very slow catalysis, whereas for electronwithdrawing groups, much higher reactivity is noted (entries 8-9). Since the supramolecular ligands can form diphosphine $\mathrm{Rh}$ complexes, the resultant activity is probably the sum of electronic and steric features. Another interesting result is obtained with the $\mathrm{Ru}(\mathrm{II})$ porphyrin building block 11, which gives the highest catalytic rate, likely as a result of electronic effects. It is known that $\mathrm{Ru}(\mathrm{II})$ porphyrins show much higher
Table 1. Rhodium-Catalyzed Hydroformylation of 1-Octene with the Pyridylphosphine-Zn(II)porphyrins Ligand Assemblies Based on Building Blocks 1-10 ${ }^{a, b}$

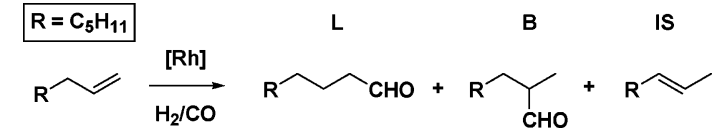

\begin{tabular}{cllcccc}
\hline entry & ligand & \multicolumn{1}{c}{ meso-R } & $\begin{array}{c}\text { conv } \\
(\%)\end{array}$ & $\begin{array}{c}\mathbf{I S}^{c} \\
(\%)\end{array}$ & $\begin{array}{r}\text { TOF } \\
\left(\mathrm{h}^{-1}\right)\end{array}$ & $\begin{array}{c}\mathbf{L} \\
(\%)\end{array}$ \\
\hline 1 & $\mathbf{1}$ & - & 28 & 0.8 & 18 & 78 \\
2 & $\mathbf{1} \cdot[\mathbf{2}]_{3}$ & $\mathrm{H}$ & 26 & 1.0 & 17 & 81 \\
3 & $\mathbf{1} \cdot[\mathbf{3}]_{3}$ & $p$-tBu & 14 & 0.9 & 9 & 81 \\
4 & $\mathbf{1} \cdot[\mathbf{4}]_{3}$ & $p$-OAc & 21 & 0.9 & 14 & 79 \\
5 & $\mathbf{1} \cdot[\mathbf{5}]_{3}$ & $p$-OMe & 2 & 7.7 & 1 & 74 \\
6 & $\mathbf{1} \cdot[\mathbf{6}]_{3}$ & $m, m$-OMe & 1 & 12 & 1 & 79 \\
7 & $\mathbf{1} \cdot[7]_{3}$ & $p$-OC $16 \mathrm{H}_{33}$ & 5 & 3.3 & 3 & 81 \\
8 & $\mathbf{1} \cdot[\mathbf{8}]_{3}$ & penta-F & 25 & 1.0 & 16 & 79 \\
9 & $\mathbf{1} \cdot[\mathbf{9}]_{3}$ & $p$-NO & 12 & 0.3 & 8 & 78 \\
10 & $\mathbf{1} \cdot[\mathbf{1 0}]_{3}$ & $\mathrm{H}(\mathrm{M}=\mathrm{Ru})$ & 38 & 0.8 & 25 & 81
\end{tabular}

a Abbreviations: $\mathrm{L}=$ linear, $\mathrm{B}=$ branched, IS $=$ isomerization level, TOF $=$ average turnover frequency. ${ }^{b}$ Conditions: $t=16 \mathrm{~h}, T=25^{\circ} \mathrm{C}, P$ $=20 \mathrm{bar} \mathrm{CO} / \mathrm{H}_{2}(1: 1)$, [phosphine] $=9.3 \mathrm{mM},[\mathrm{Rh}]=1.7 \mathrm{mM}$, decane as internal standard. ${ }^{c}$ Based on converted 1-octene.

association with pyridines than their respective $\mathrm{Zn}$ analogues, ${ }^{5}$ and the exchange rate is much lower, which may also partly account for the results obtained.

In summary, we report a rare supramolecular structure in which penta- and hexacoordinated $\mathrm{Zn}$ (II)porphyrins coexist. The six-coordinate $\mathrm{Zn}$ complex acts as a bridging unit between the two parts of the assembly, thereby enabling a lower 2:1 stoichiometry (5:2) as compared to the expected $3: 1$ ratio as found in solution (UV-vis). This coordination behavior is likely a result of crystal packing effects and $\pi-\pi$ interactions between the porphyrin rings. The preliminary catalysis data indicate that the phosphine assemblies give rise to diphosphine metal complexes, in which the reactivity is controlled by the substitution pattern of the meso-phenyl groups. Currently, we are expanding this series of sterically demanding, supramolecular phosphine assemblies toward systems based on chiral building blocks and the use of generally more appealing substrates and other organic transformations.

Acknowledgment. The Netherlands Organization for Scientific Research (NWO) and the University of Amsterdam are gratefully acknowledged for financial support (VICIprogram). D.M.T. and A.L.S. thank the University of Utrecht and NWO for a financial contribution. We kindly acknowledge Prof. P. W. N. M. van Leeuwen for fruitful discussions.

Supporting Information Available: Crystallographic details for $[1]_{2} \cdot[2]_{5}$ in CIF format and experimental details. This material is available free of charge via the Internet at http://pubs.acs.org. IC050858V 